\title{
Ultrastructural observations of fertilization in the Japanese long-fingered bat, Miniopterus schreibersii fuliginosus
}

\author{
T. Mōri and T. A. Uchida \\ Zoological Laboratory, Faculty of Agriculture, Kyushu University, Fukuoka 812, Japan
}

\begin{abstract}
Summary. Only a very few spermatozoa were found in the ampulla of the oviduct just after ovulation. The spermatozoa lost both the acrosome cap and the equatorial segment while passing between the cumulus cells surrounding an ampullar egg; many such spermatozoa were found in the perivitelline space. One spermatozoon was seen in contact with the plasma membrane of the ovum in the metaphase of the second meiotic division. Excess spermatozoa in the perivitelline space were phagocytosed by pseudopodial protrusions from the blastomere surface.
\end{abstract}

\section{Introduction}

Studies of the process of fertilization in bats consist of a few light microscope observations for Pipistrellus abramus (Uchida, 1953; Hiraiwa \& Uchida, 1956), Noctilio albiventris (Rasweiler, 1977) and Miniopterus schreibersii (Wallace, 1978). Uchida \& Möri (1974) have commented briefly on the acrosome reaction of spermatozoa in the long-fingered bat, Miniopterus schreibersii fuliginosus, although the process of fertilization itself was not discussed. In this bat, copulation in mid-October is followed closely by ovulation, and the single oocyte, always discharged from the left ovary, is fertilized by a spermatozoon in the ampulla of the left oviduct (Uchida, 1957). The aim of the present study was to examine with the electron microscope the process of fertilization in vivo in this bat.

\section{Materials and Methods}

Twenty-five adult females were collected at Ibarayama, an abandoned mine $\left(33.5^{\circ} \mathrm{N}\right)$ in the Fukuoka Prefecture, and Ohse-do Cave $\left(32.5^{\circ} \mathrm{N}\right)$ in the Kumamoto Prefecture in mid-October of 1970-1979. After the females were perfused with $3 \%$ glutaraldehyde in $0.2 \mathrm{M}$-phosphate buffer at pH 7.2 under ether anaesthesia, the left oviducts were removed and further fixed for $3 \mathrm{~h}$ in cold $1.3 \%$ osmium tetroxide buffered with the same buffer, dehydrated with acetone and embedded in Epon 812 . Thick serial sections $(1.5 \mu \mathrm{m})$ for light microscopy were cut with glass knives on a Porter-Blum MT-2B microtome, applied to a glass slide heated to $60^{\circ} \mathrm{C}$, and stained with $0.5 \%$ toluidine blue. Thin sections $(\sim 60 \mathrm{~nm})$ were then taken from suitable thick sections by the method of Öura \& Usuku (1976), and doubly stained with uranyl and lead acetate before examination in an Hitachi HS-9 electron microscope $(75 \mathrm{kV})$. Amongst the 25 females, 4 had unfertilized eggs, 12 had a fertilized egg, and in 9 cleavage had started. The total number of spermatozoa observed was 149, i.e. 20 in the ampulla, 13 in the cumulus cell layer, 12 in the zona pellucida and 104 in the perivitelline space. 


\section{PLATES $1-4$}

Abbreviations: A, acrosome; Al, ampullar lumen; B, blastomere; C, cumulus cell; $\mathrm{Cc}$, cell of corona radiata; $\mathrm{Cg}$, cortical granule; $\mathrm{E}$, egg; Epm, egg plasma membrane; Es, equatorial segment; Fp, first polar body; I, incorporation cone; Iam, inner acrosomal membrane; L, lamellar structure; $\mathrm{M}$, microvilli; $\mathrm{Mb}$, mid body; $\mathrm{Mp}$, middle piece; $\mathrm{Mpn}$, male pronucleus; Oam, outer acrosomal membrane; P, principal piece; Pas, postacrosomal sheath; Pp, pseudopodial protrusion; Ps, penetration slit; Pv, perivitelline space; S, spermatozoon; Sh, sperm head; Sm, stout microvilli; Sp, second polar body; Spm, sperm plasma membrane; V, vesicle; W, wall of ampulla; $Z$, zona pellucida; ${ }^{*}$, region of loss of the equatorial segment.

\section{PLATE 1}

Figs 1 and 2. Light micrograph of a horizontal section (Fig. 1) and an electron micrograph of a sagittal section (Fig. 2) of the sperm head of an acrosome-intact spermatozoon found in the middle portion of the ampulla.

Fig. 3. Light micrograph of an unfertilized egg in the middle portion of the ampulla.

Fig. 4. Electron micrograph of the zona pellucida of the same egg as in Fig. 3, showing the rough granular consistency.

Fig. 5. A sperm head passing between the cumulus cells is shown.

Fig. 6. The sperm head in Fig. 5 at higher magnification reveals that the acrosome cap and equatorial segment have been lost and the inner acrosomal membrane is clearly continuous with the plasma membrane overlying the post-acrosomal sheath region.

Fig. 7. An acrosome-reacted spermatozoon from the lumen of the utero-tubal junction. Note the intact equatorial segment.

\section{PLATE 2}

Fig. 8. Electron micrograph of a spermatozoon passing through the zona pellucida leaving a curved slit behind it.

Fig. 9. The sperm head in Fig. 8 at higher magnification, showing the similarity of the morphological changes to the sperm head in Fig. 6.

Figs 10 and 11. A spermatozoon binding to the plasma membrane of an ovum. The post-acrosomal sheath region of the spermatozoon is in contact with the egg surface devoid of microvilli (Fig. 10). The sperm tail lies on the egg surface in a region with stout microvilli (Fig. 11). Inset: cortical granules of the unfertilized egg.

\section{PLATE 3}

Figs 12-15. Electron micrographs showing an egg in an early stage of development of the male and female pronuclei. A swelling male pronucleus in the incorporation cone devoid of microvilli is shown (Fig. 12). Inset: the zona pellucida of the fertilized egg. The sperm middle piece near the male pronucleus (Fig. 13) and principal piece distant from it (Fig. 14) are shown. The female pronucleus at some distance from the male pronucleus contains lamellar structures (Fig. 15).

Figs 16-19. Electron micrographs of an egg in a more advanced stage of pronucleus formation than that illustrated in Figs 12-15, showing the male pronucleus in the incorporation cone (Fig. 16), the nearby female pronucleus (Fig. 17), the extruded second polar body (Fig. 18), and neck and middle piece of another spermatozoon which entered the first polar body (Fig. 19).

\section{PLATE 4}

Figs 20-23. Electron micrographs showing the elimination of excess spermatozoa in the perivitelline space of a morula. General features of the surface blastomeres engulfing spermatozoa are shown (Fig. 20). Spermatozoa being phagocytosed by the pseudopodial protrusions (Figs 21 and 22) and a digested sperm head (Fig. 23) are observed. 
PLATE 1
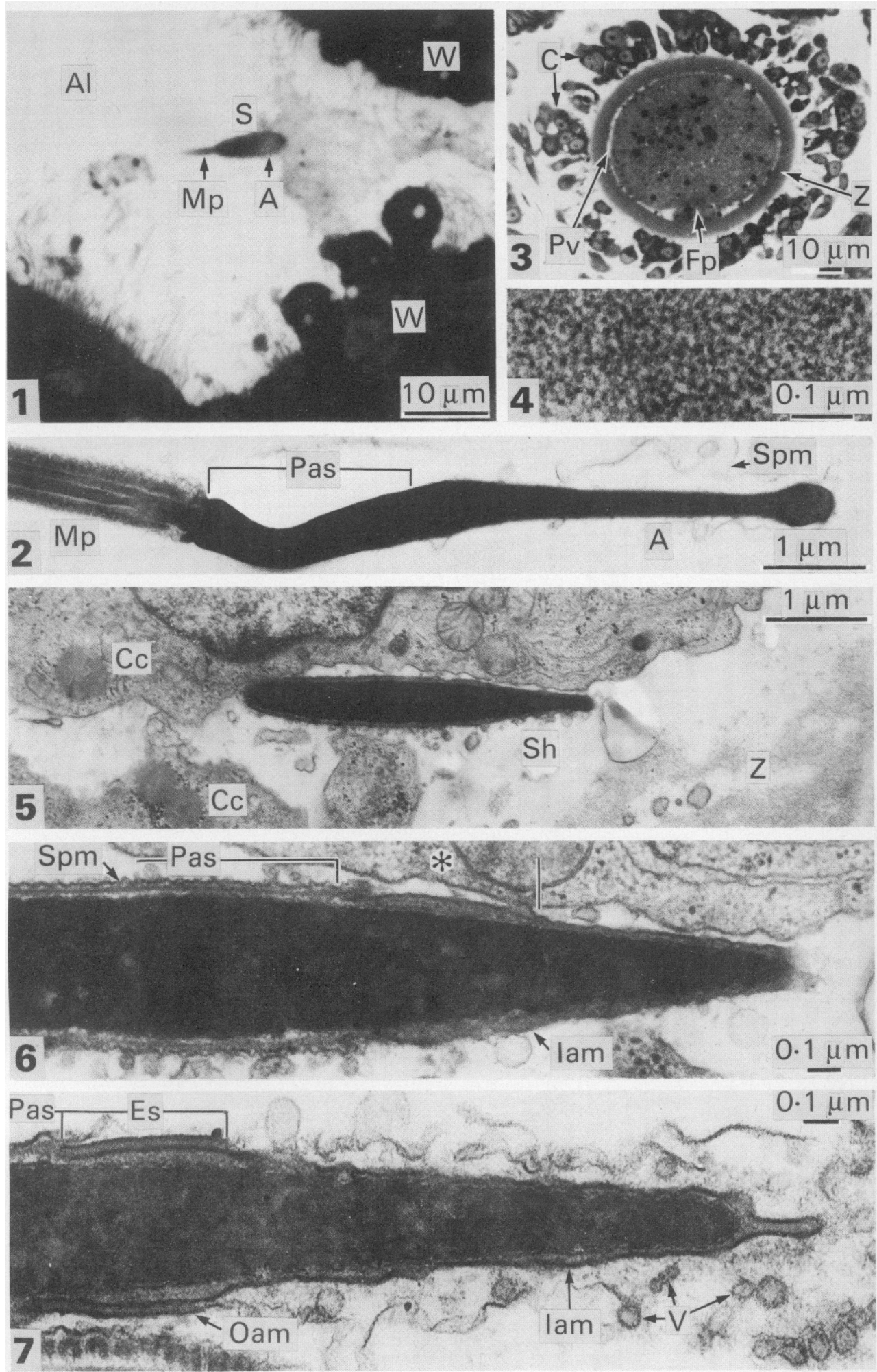

(Facing p. 232) 


\section{PLATE 2}

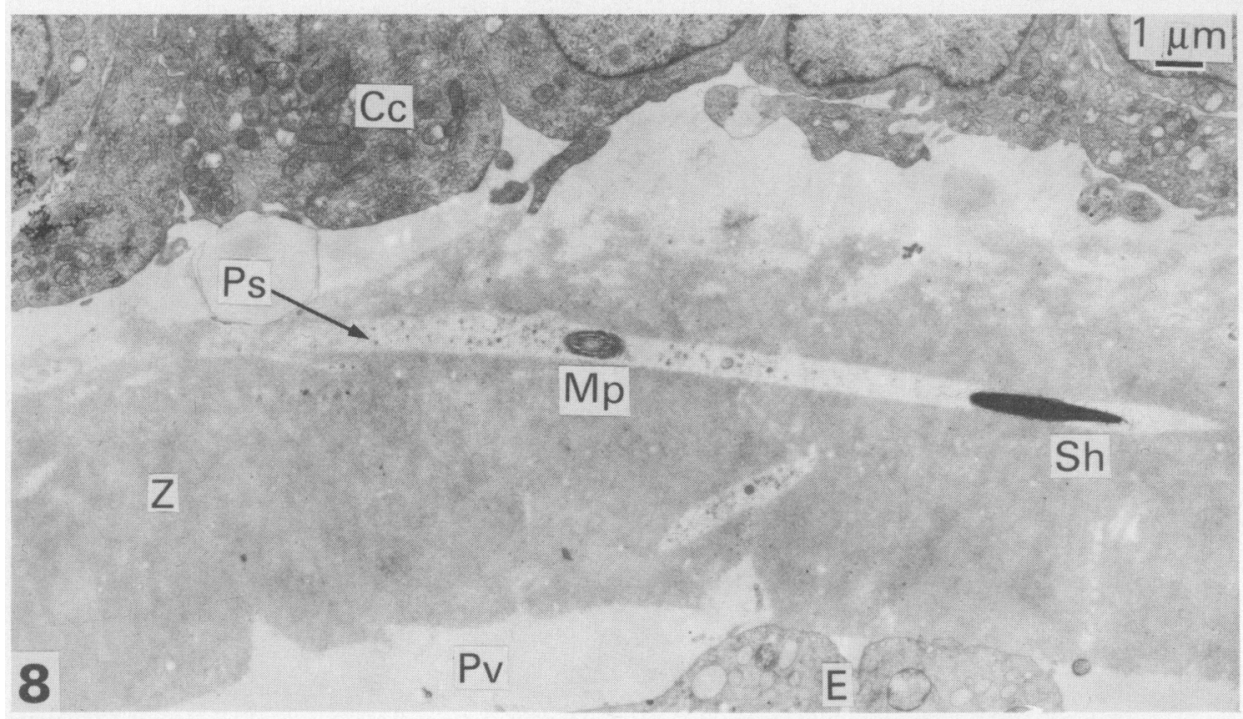

976e-Pas -

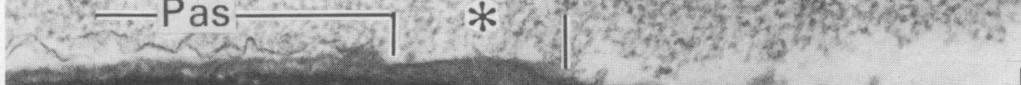
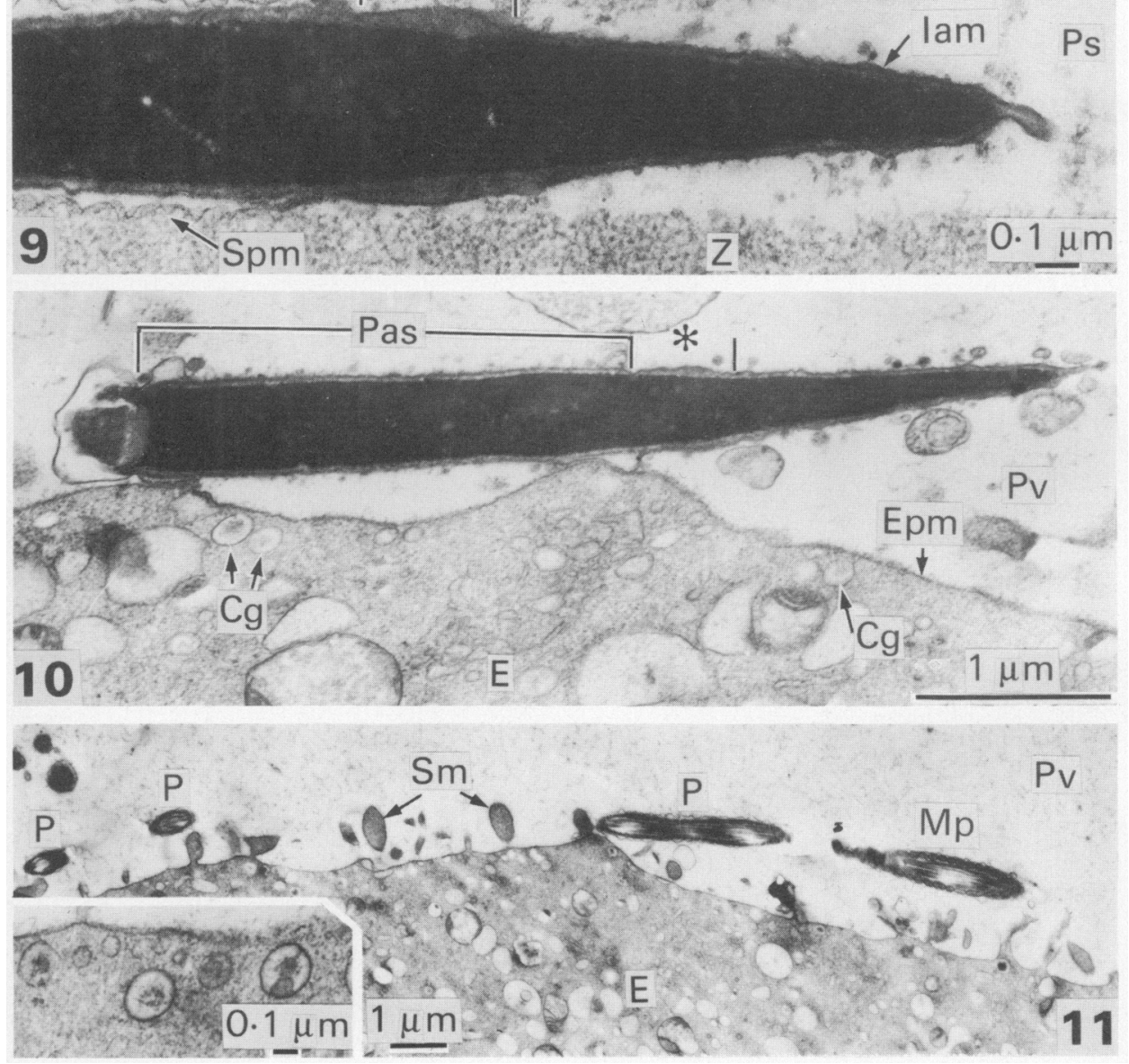


\section{PLATE 3}
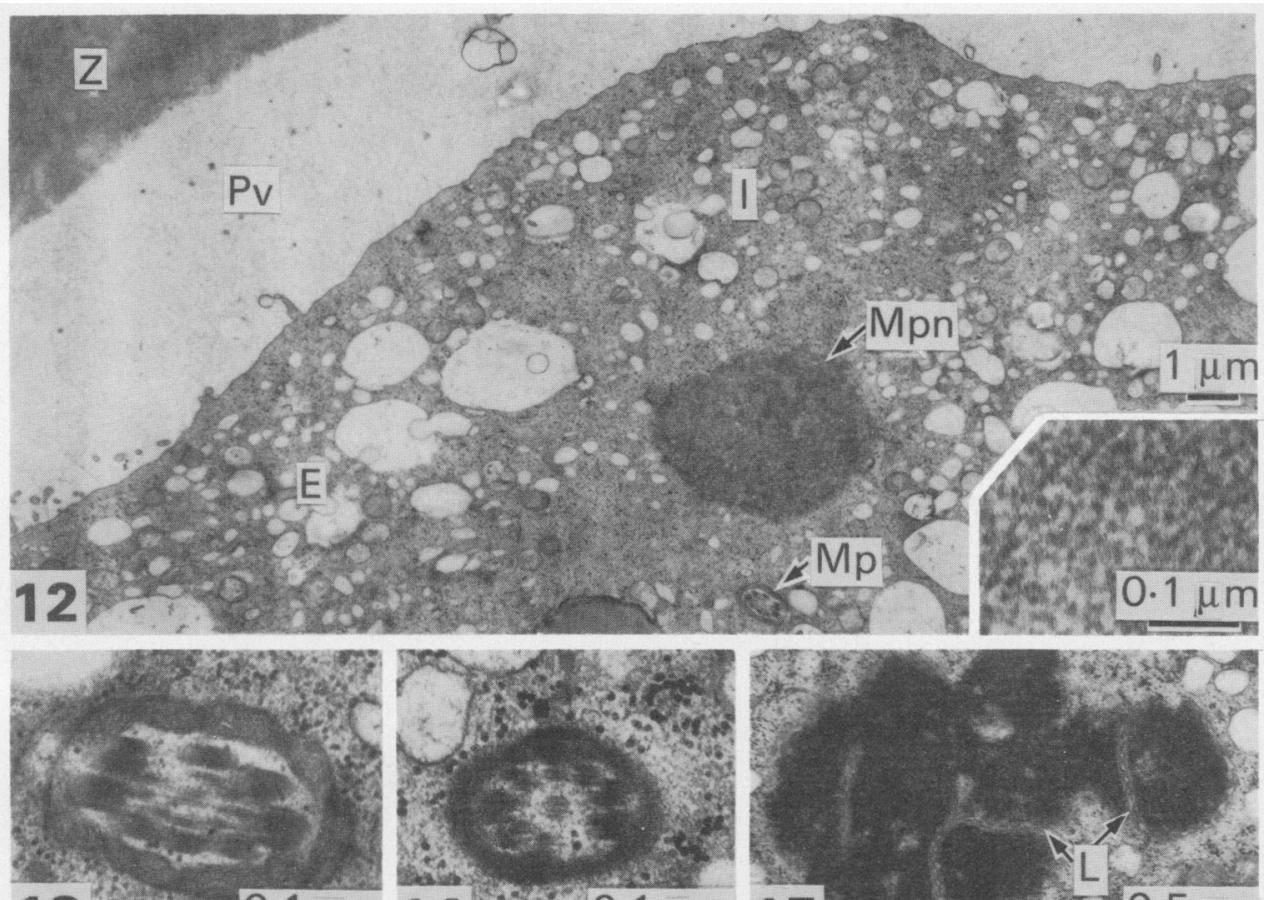

$13 .-0.1 \mu \mathrm{m} 14=0.1 \mu \mathrm{m}$
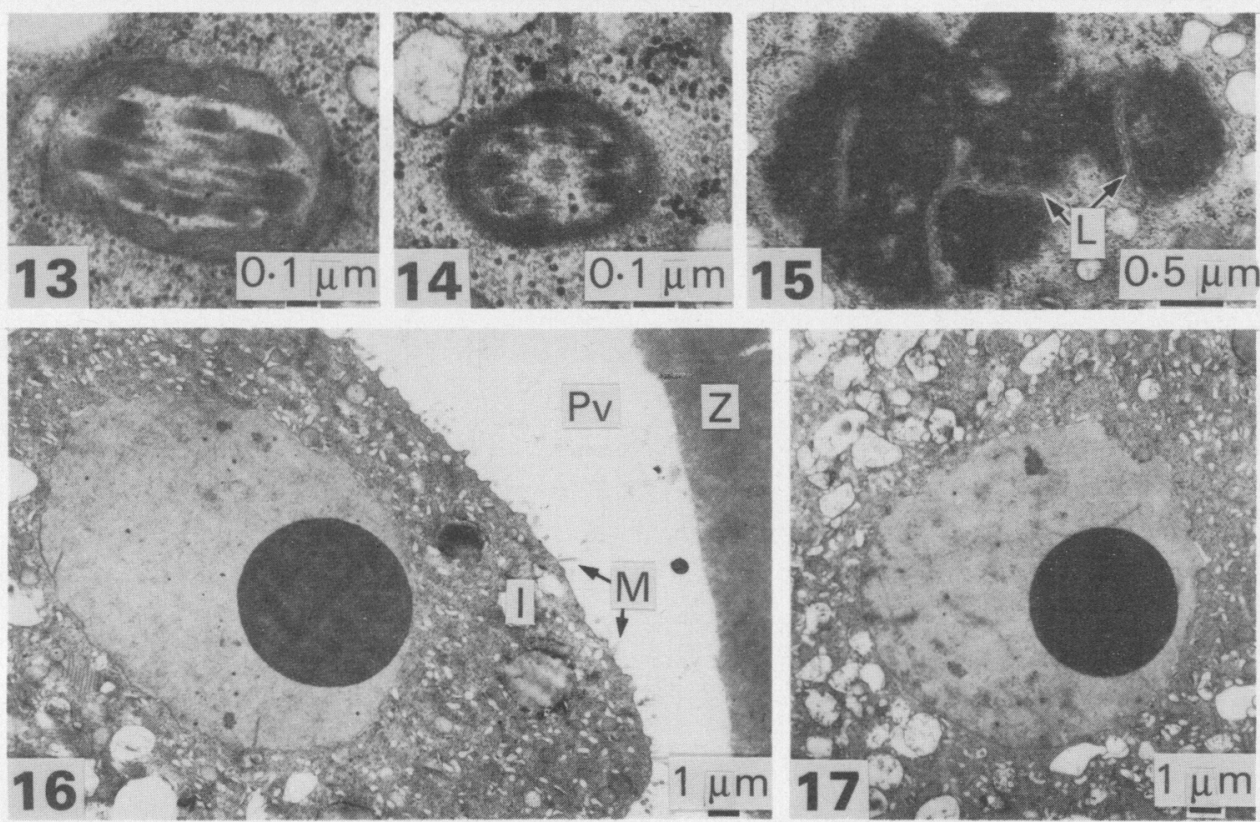

16. and -1
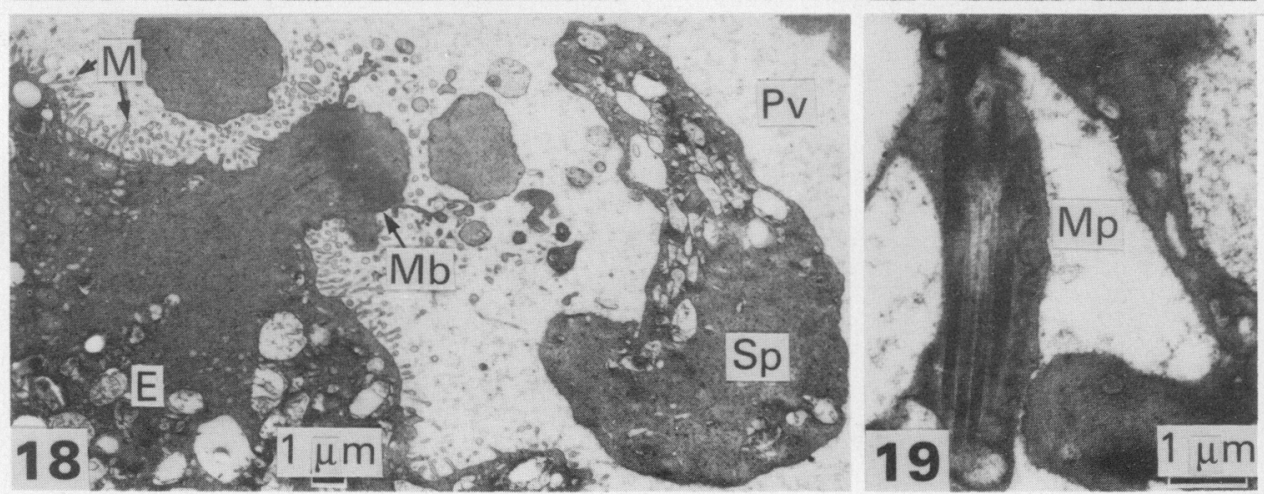
PLATE 4

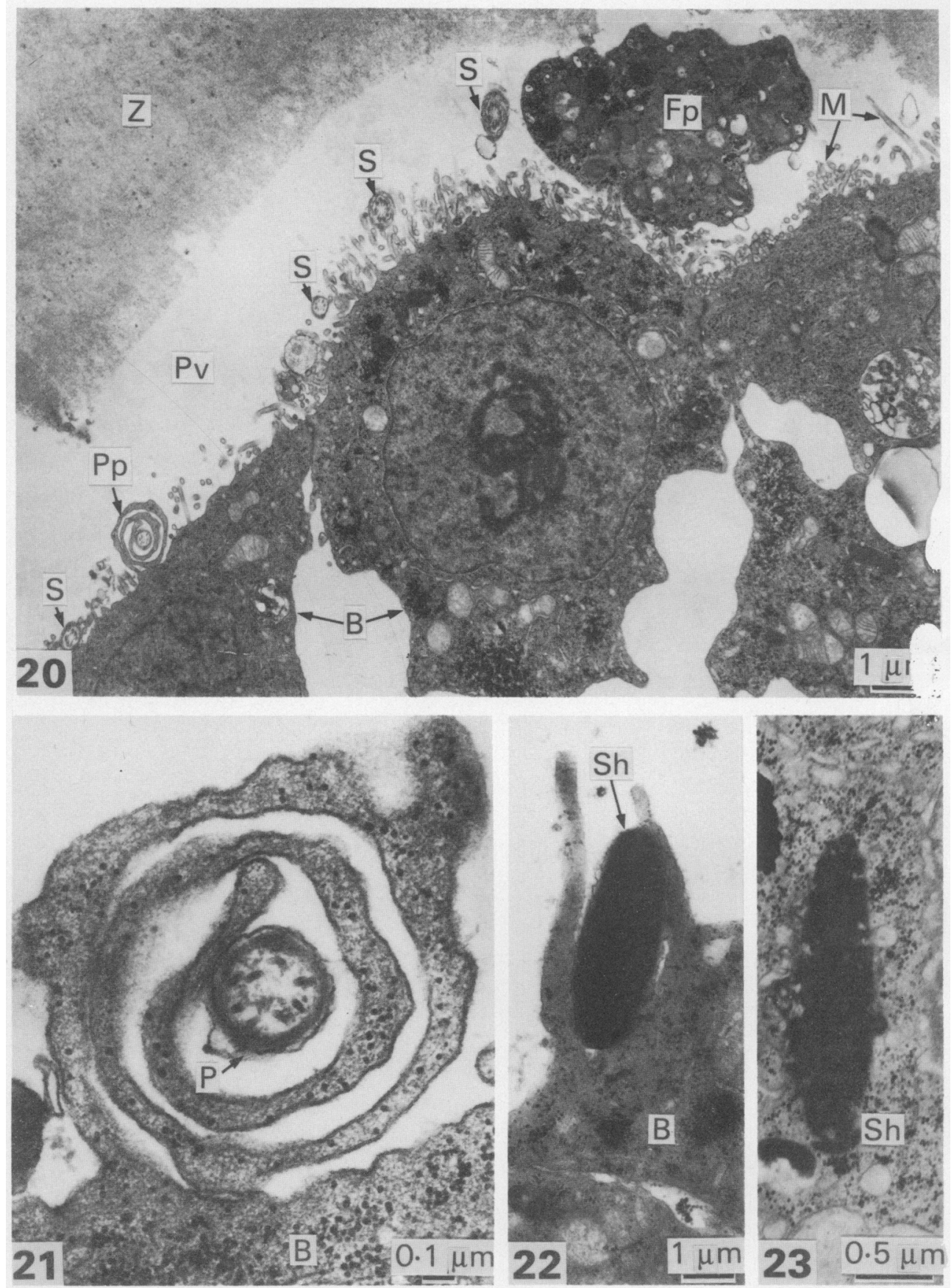




\section{Results}

\section{Spermatozoa passing through the egg envelopes}

Only a very few spermatozoa were present in the ampulla of the left oviduct just after ovulation (Pl. 1, Figs 1 and 2). An oocyte in the ampulla (Pl. 1, Fig. 3) was surrounded by the egg envelopes, i.e. a few layers of cumulus cells and the zona pellucida consisting of a rough granular substance (Pl. 1, Fig. 4). Spermatozoa which reached the egg envelopes showed an acrosome reaction when in contact with the extracellular matrix surrounding the cumulus cells; the plasma membrane and outer acrosomal membrane of both the acrosome cap and the equatorial segment regions were lost by fusion ( $\mathrm{Pl}$. 1, Figs 5 and 6). A few spermatozoa seen free in the lumen of the uterotubal junction had lost the acrosome cap, but still had an intact equatorial segment (Pl. 1, Fig. 7).

A spermatozoon that had moved through the zona pellucida left a curved slit behind it (Pl. 2, Fig. 8). Spermatozoa observed in the perivitelline space were morphologically similar (Pl. 2, Fig. 9) to those found between the cumulus cells (Pl. 1, Fig. 6).

\section{rtilization}

One of the spermatozoa which had entered the perivitelline space was in contact with the pli na membrane of an ovum in metaphase of the second meiotic division. The post-acrosomal sheath area of the spermatozoon was apposed to an area of the egg surface devoid of microvilli (Pl. 2, Fig. 10), while the sperm tail was in contact with stout microvilli on the egg surface (PI. 2, Fig. 1); cortical granules were still present (PI. 2, Fig. 11, inset). Two degenerated spermatozoa W. also seen in the perivitelline space of this ovum.

nithough the first step in sperm-egg fusion was not observed, an ovum with an incorporation cone which was devoid of microvilli and included a swelling male pronucleus was recognized (Pl. 3, Fig. 12). The middle piece (Pl. 3, Fig. 13) and principal piece (Pl. 3, Fig. 14) of the spermatozoon, and a chromatin mass of the female pronucleus divided into sub-areas by lamellar structures, resembling annulate lamellae except that they were not found stacked (PI. 3, Fig. 15), were observed in the egg cytoplasm. There was no apparent difference in structure of the zona pellucida round an unfertilized egg with cortical granules (Pl. 1, Fig. 4) and that round a fertilized egg which had lost the granules by the cortical reaction (Pl. 3, Fig. 12, inset).

When a single large, round nucleolus became visible within the male and female pronuclei (Pl. 3, Figs 16 and 17), slender microvilli appeared on the whole surface of the incorporation cone (Pl. 3, Fig. 16); on the rest of the egg surface, the stout microvilli became slender microvilli (Pl. 3, Fig. 18). At this stage, extrusion of the second polar body was completed (Pl. 3, Fig. 18). Another spermatozoon was seen penetrating the first polar body in mitosis (Pl. 3, Fig. 19).

\section{Elimination of the excess spermatozoa in the perivitelline space}

While the egg fertilized in the middle ampulla was descending into the ampullary-isthmic junction, the number of spermatozoa entering the perivitelline space increased and a maximum of 102 was recorded. These excess spermatozoa degenerated rapidly; in a 32-celled morula, the spermatozoa were phagocytosed by pseudopodial protrusions of the surface blastomeres (Pl. 4, Figs 20-22), and were digested and absorbed in the cells (Pl. 4, Fig. 23).

\section{Discussion}

Electron microscopic analyses of the mechanism of fertilization in mammals have been extensive, e.g. in the rat, mouse, golden hamster, guinea-pig and cow (Noda \& Yanagimachi, 1976; Oura \& Yasuzumi, 1976). For wild mammals, however, there have been few such studies. 
The morphological changes in the acrosome reaction of spermatozoa passing through the egg envelopes vary with the species. In the rabbit, spermatozoa passing between the cumulus cells both in vitro (Bedford, 1968) and in vivo (Bedford, 1972) lose the acrosome cap, but the equatorial segment remains intact even when the spermatozoa have reached the perivitelline space. In the golden hamster (Yanagimachi \& Noda, 1970a, b, c), mouse (Stefanini, Oura \& Zamboni, 1969) and pig (Szöllösi \& Hunter, 1973, 1978), spermatozoa lose the acrosome cap while passing through the cumulus cell layer and lose the equatorial segment in the zona pellucida. The equatorial segment may be lost in vitro by vesiculation of the outer acrosomal membrane in golden hamsters and pigs. In the hamster in vivo, however, the plasma membrane ruptures intermittently during passage between the cumulus cells, and when the sperm head penetrates the zona pellucida, the membrane remnants, which are considered to consist of the outer acrosomal membrane and the ruptured plasma membrane of the equatorial segment, are discarded at the top of the penetration slit (Ōura \& Yasuzumi, 1976). In the long-fingered bat, spermatozoa passing between the cumulus cells lose not only the acrosome cap but also the equatorial segment, and yet they are still able to penetrate the zona pellucida although hamster spermatozoa capacitated in vitro and therefore without the the equatorial segment fail to pass through the zona pellucida (Barros, Fujimoto \& Yanagimachi, 1973).

In the long-fingered bat, spermatozoa are stored in the utero-tubal junction (Uchida \& Móri, 1974; Móri \& Uchida, 1980). The spermatozoa in contact with the epithelial cells have not undergone the acrosome reaction and are not capacitated. However, a few spermatozoa free in the lumen appear to be incompletely capacitated, because there is a partial acrosome reaction which is restricted to the acrosome cap but leaves the equatorial segment intact. It is therefore assumed that only a very few spermatozoa can undergo full capacitation while ascending the oviduct just after ovulation; most of the spermatozoa become completely capacitated and exhibit the full acrosome reaction only when passing through the cumulus cell layer.

Mammalian eggs appear to have two independent devices to protect against polyspermy, i.e. the zona reaction and vitelline block; the former is highly developed in the golden hamster (Austin \& Braden, 1956; Barros \& Yanagimachi, 1971; Yanagimachi, 1977) and cow (Brackett, Oh, Evans \& Donawick, 1980) and the latter is prominent in the rabbit (Austin \& Braden, 1956), but both processes play a role in keeping out excess spermatozoa in the mouse and rat (Austin \& Braden, 1956). In the long-fingered bat, completely acrosome-reacted spermatozoa continue to invade the perivitelline space even after fertilization, and the block to polyspermy therefore resides in the egg plasma membrane, as in the rabbit.

The excess spermatozoa in the perivitelline space of the bat degenerate rapidly and undergo phagocytosis by pseudopodial protrusions of the surface blastomeres. Such a phenomenon has not been observed in other mammals, so far as is known, but it appears to be an effective means for elimination of the excess spermatozoa in the perivitelline space.

We thank Professor E. W. Jameson, Jr, University of California, for comments on the manuscript.

\section{References}

Austin, C.R. \& Braden, A.W.H. (1956) Early reaction of the rodent egg to spermatozoon penetration. $J$. exp. Biol. 33, 358-365.

Barros, C. \& Yanagimachi, R. (1971) Induction of zona reaction in golden hamster eggs by cortical granule material. Nature, Lond. 233, 268-269.

Barros, C., Fujimoto, M. \& Yanagimachi, R. (1973) Failure of zona penetration of hamster spermatozoa after prolonged preincubation in a blood serum fraction. J. Reprod. Fert. 35, 89-95.
Bedford, J.M. (1968) Ultrastructural changes in the sperm head during fertilization in the rabbit. $A m . J$. Anat. 123, 329-358.

Bedford, J.M. (1972) An electron microscopic study of sperm penetration into the rabbit egg after natural mating. Am. J. Anat. 133, 213-254.

Brackett, B.G., Oh, Y.K., Evans, J.F. \& Donawick, W.J. (1980) Fertilization and early development of cow ova. Biol. Reprod. 23, 189-205.

Hiraiwa, Y.K. \& Uchida, T. (1956) Fertilization in the 
bat, Pipistrellus abramus abramus (Temminck). III. Fertilizing capacity of spermatozoa stored in the uterus after the copulation in the fall. Sci. Bull. Fac. Agr. Kyushu Univ. 15, 565-574. [In Japanese with English summary.]

Mōri, T. \& Uchida, T.A. (1980) Sperm storage in the reproductive tract of the female Japanese longfingered bat, Miniopterus schreibersii fuliginosus. $J$. Reprod. Fert. 58, 429-433.

Noda, Y.D. \& Yanagimachi, R. (1976) Electron microscopic observations of guinea pig spermatozoa penetrating eggs in vitro. Develop., Growth and Different. 18, 15-23.

Öura, C. \& Usuku, G. (1976) Ultrathin-sectioning of the limited area for electron microscopy from serial one micron sections. Okajimas Fol. anat. jap. 52, 331-340.

Ōura, C. Yasuzumi, F. (1976) Electron microscope study on the sperm head passing through the zona pellucida of the hamster egg in vivo. Gunma Symposia on Endocrinology 13, 141-158.

Rasweiler, IV, J.J. (1977) Preimplantation development, fate of the zona pellucida, and observations on the glycogen-rich oviduct of the little bulldog bat, Noctilio albiventris. Am. J. Anat. 150, 269-300.

Stefanini, M., Ōura, C. \& Zamboni, L. (1969) Ultrastructure of fertilization in the mouse. 2. Penetration of sperm into the ovum. J. Submicrosc. Cytol. 1, $1-23$.

Szöllösi, D. \& Hunter, R.H.F. (1973) Ultrastructural aspects of fertilization in the domestic pig: sperm penetration and pronucleus formation. J. Anat. 116, 181-206.

Szölösi, D. \& Hunter, R.H.F. (1978) The nature and occurrence of the acrosome reaction in spermatozoa of the domestic pig, Sus scrofa.J. Anat. 127, 33-41.
Uchida, T. (1953) Studies on the embryology of the Japanese house bat, Pipistrellus tralatitius abramus (Temminck). II. From the maturation of the ova to the fertilization, especially on the behaviour of the follicle cells at the period of fertilization. Sci. Bull. Fac. Agr. Kyushu Univ. 14, 153-168. [In Japanese with English summary.]

Uchida, T.A. (1957) Fertilization and hibernation in bats. Heredity, Tokyo 11, 14-17. [In Japanese.]

Uchida, T.A. \& Möri, T. (1974) Electron microscopic analysis of the mechanism of fertilization in Chiroptera. I. Acrosomal reaction and consequence to death of the sperm in the Japanese long-fingered bat, Miniopterus schreibersi fuliginosus. Sci. Bull. Fac. Agr. Kyushu Univ. 28, 117-184. [In Japanese with English summary.]

Wallace, G.I. (1978) A histological study of the early stages of pregnancy in the bent-winged bat (Miniopterus schreibersii) in north-eastern New South Wales, Australia ( $30^{\circ} 27^{\prime}$ S). J. Zool., Lond. 185, 519-537.

Yanagimachi, R. (1977) Specificity of sperm-egg interaction. In Immunobiology of Gametes, pp. 255-289. Eds M. Edidin \& M. H. Johnson. Cambridge University Press.

Yanagimachi, R. \& Noda, Y.D. (1970a) Electron microscope studies of sperm incorporation into the golden hamster egg. Am.J. Anat. 128, 429-462.

Yanagimachi, R. \& Noda, Y.D. (1970b) Ultrastructural changes in the hamster sperm head during fertilization. J. Ultrastruct. Res. 31, 465-485.

Yanagimachi, R. \& Noda, Y.D. (1970c) Physiological changes in the postnuclear cap region of mammalian spermatozoa: a necessary preliminary to the membrane fusion between sperm and egg cells. $J$. Ultrastruct. Res. 31, 486-493.

Received 22 January 1981 